\title{
Vitamin D deficiency impairs skeletal muscle function in a smoking mouse model
}

\author{
Nele Cielen', Nele Heulens', Karen Maes', Geert Carmeliet², Chantal Mathieu², \\ Wim Janssens ${ }^{1}$ and Ghislaine Gayan-Ramirez ${ }^{1}$ \\ 'Laboratory of Respiratory Diseases, Department of Clinical and Experimental Medicine, KULeuven, \\ Leuven, Belgium \\ 2Laboratory of Clinical and Experimental Endocrinology, Department of Clinical and Experimental \\ Medicine, KULeuven, Leuven, Belgium
}

Correspondence should be addressed to G Gayan-Ramirez Email

ghislaine.gayan-ramirez@ med.kuleuven.be

\begin{abstract}
Chronic obstructive pulmonary disease (COPD) is associated with skeletal muscle dysfunction. Vitamin D plays an important role in muscle strength and performance in healthy individuals. Vitamin D deficiency is highly prevalent in COPD, but its role in skeletal muscle dysfunction remains unclear. We examined the time-course effect of vitamin D deficiency on limb muscle function in mice with normal or deficient vitamin $D$ serum levels exposed to air or cigarette smoke for 6, 12 or 18 weeks. The synergy of smoking and vitamin D deficiency increased lung inflammation and lung compliance from 6 weeks on with highest emphysema scores observed at 18 weeks. Smoking reduced body and muscle mass of the soleus and extensor digitorum longus (EDL), but did not affect contractility, despite type II atrophy. Vitamin D deficiency did not alter muscle mass but reduced muscle force over time, downregulated vitamin D receptor expression, and increased muscle lipid peroxidation but did not alter actin and myosin expression, fiber dimensions or twitch relaxation time. The combined effect of smoking and vitamin $D$ deficiency did not further deteriorate muscle function but worsened soleus mass loss and EDL fiber atrophy at 18 weeks. We conclude that the synergy of smoking and vitamin D deficiency in contrast to its effect on lung disease, had different, independent but important noxious effects on skeletal muscles in a mouse model of mild COPD.
\end{abstract}
Key Words
$\checkmark$ COPD
- muscle function
- muscle atrophy
- oxidative stress
- cigarette smoke exposure
- lung function

Journal of Endocrinology (2016) 229, 97-108

\section{Introduction}

Chronic obstructive pulmonary disease (COPD) is not only a lung disease, but also associates with several comorbidities. Among them, skeletal muscle dysfunction is of major concern, as it contributes, independently of lung function (Engelen et al. 2000), to decreased functional capacity (Gosselink et al. 1996), poor quality of life (Simpson et al. 1992), increased health care utilization (Decramer et al. 1997), and even mortality (Swallow et al. 2007). In addition to smoking, physical inactivity, oxidative stress, and systemic inflammation, other factors such as vitamin D deficiency may contribute to the large variability in the prevalence and severity of skeletal muscle dysfunction in COPD (Maltais et al. 2014).

Low serum levels of vitamin D are known to be associated with reduced muscle strength and performance, and lead to muscle atrophy, increased apoptosis, decreased protein synthesis, and perturbation in intracellular calcium homeostasis (Ceglia \& Harris 2013). Most of these alterations are also observed in the skeletal muscles of 
patients with COPD (Agusti et al. 2002, Doucet et al. 2007, Plant et al. 2010). In addition, vitamin D deficiency, defined as serum levels of 25-hydroxyvitamin D (25-(OH)D) below $20 \mathrm{ng} / \mathrm{ml}(50 \mathrm{nmol} / \mathrm{l})$, is highly prevalent in patients with COPD and increases with the severity of the disease (Janssens et al. 2009, 2010). However, the association between vitamin $\mathrm{D}$ serum levels and muscle strength, as proven in controls, was not observed in COPD patients (Jackson et al. 2013), suggesting that some patients may represent resistance to the actions of vitamin D (Jackson et al. 2013). Interestingly, a relationship between variants of the vitamin $\mathrm{D}$ receptor (VDR) and skeletal muscle strength was observed in patients with COPD (Hopkinson et al. 2008).

Although the involvement of vitamin D deficiency on skeletal muscle dysfunction in patients with COPD is unclear, several studies suggest a potential link. First, the high levels of parathyroid hormone as observed in patients with COPD (Jackson et al. 2013) may enhance the risk of sarcopenia (Visser et al. 2003) and accentuate an agerelated reduction in VDR expression (Bischoff-Ferrari et al. 2004a) and muscle strength (Bischoff-Ferrari et al. 2004b). Furthermore, cigarette smoke exposure has been shown to increase the risk for vitamin D deficiency (Cutillas-Marco et al. 2012) which may enhance the risk for sarcopenia by impairing muscle protein synthesis (Petersen et al. 2007). In mice, smoking downregulates PGC1- $\alpha$ (Tang et al. 2010) which serves as a co-activator for VDR (Savkur et al. 2005) thereby affecting skeletal muscle function. Apart from hypocalcemia, hypophosphatemia, and secondary hyperparathyroidism (Li et al. 1997, Yoshizawa et al. 1997, Song et al. 2003), Vdr-knockout mice also exhibited generalized fiber atrophy and alterations in myogenic differentiation pathway (Endo et al. 2003). Finally, in cell culture studies, cigarette smoke is found to inhibit vitamin D induced-VDR translocation (Uh et al. 2012) and to impair several of the vitamin D actions on skeletal muscle cells (Liu et al. 2011).

To investigate whether vitamin $\mathrm{D}$ deficiency per se may play a role in skeletal muscle dysfunction in COPD, we examined the time-course effect of chronic vitamin D deficiency on skeletal muscle function in a smoking mouse model. We used a vitamin D-deficient mouse model with normalized calcium and phosphorus serum levels by giving mice a rescue diet from gestation onward (Johnson \& DeLuca 2002) and exposed them to cigarette smoke or room air for 6,12 , or 18 weeks. We hypothesized that vitamin D deficiency per se would exert detrimental effects on skeletal muscle, which would be potentiated when combined with smoking.

\section{Materials and methods}

\section{Animals}

Vitamin D deficiency was induced in $\mathrm{C} 57 \mathrm{Bl} / 6$ mice by keeping them in an ultraviolet (UV) light-free environment and by feeding them a vitamin D-depleted diet $(<200 \mathrm{IU} / \mathrm{kg}$ vitamin D) containing $20 \% \mathrm{w} / \mathrm{w}$ lactose, $2 \% \mathrm{w} / \mathrm{w}$ calcium, and $1.25 \% \mathrm{w} / \mathrm{w}$ phosphorus (Ssniff Bio-services, Uden, The Netherlands) to maintain normal calcium and phosphorus serum levels (Johnson \& DeLuca 2002). At the age of 8 weeks, breeding pairs were formed and their male offspring were used in the study. During the wholestudy experiment, these mice were kept in an UV light-free environment and received the vitamin-D depleted diet. Male C57Bl/6 mice from the same age were obtained from Harlan (Horst, The Netherlands) and used as controls. They were fed with a normal diet (Ssniff) containing $1000 \mathrm{IU} / \mathrm{kg}$ vitamin $\mathrm{D}$ to maintain the daily requirement of vitamin $\mathrm{D}$. All experimental procedures were approved by the Ethical Committee of Animal Experiments by the KULeuven.

\section{Study design}

At the age of 8 weeks, vitamin D-deficient mice $(24.4 \pm 2.0 \mathrm{~g})$ were daily exposed to breathe ambient air (D-Air, $n=42$ ) or cigarette smoke (D-Smoking, $n=40$ ) via a nose-only exposure system (InExpose system, Scireq, Paris, France). After a short acclimatization period, smoking mice were exposed to four cigarettes (Kentucky Tobacco Research and Development Center, University of Kentucky, Lexington, KY, USA), two times a day, 5 days a week (Rinaldi et al. 2012) for a period of 6,12 , or 18 weeks. They were compared with mice with sufficient vitamin D levels $(26.72 \pm 0.9 \mathrm{~g})$ exposed to ambient air (N-Air, $n=36$ ) or to cigarette smoke (N-Smoking, $n=36$ ) for the same duration (for details on number of mice per group, see Supplementary Table 1, see section on supplementary data at the end of this article). Body mass was measured weekly and total particle density concentration was measured daily (Microdust, Casella CEL, Bedford, UK). Total particle density averaged $754 \mathrm{mg}$ per $\mathrm{m}^{3}$.

\section{Pulmonary function measurements}

Twenty-four hours after the last exposure to cigarette smoke or ambient air, mice were intraperitoneally anesthetized with a mixture of xylazine $(8.5 \mathrm{mg} / \mathrm{kg}$, Rompun, Bayer) and ketamine $(130 \mathrm{mg} / \mathrm{kg}$, Ketalar, Pfizer). After tracheotomy was performed with a standard

Published by Bioscientifica Ltd. 
catheter (CNS5002, Buxco, Wilmongton, NC, USA), mice were placed in a whole-body plethysmograph with the tracheotomy catheter being connected to a computercontrolled ventilator (Buxco-Force Pulmonary Maneuvers). After a regular breathing pattern was obtained, the quasi-static pressure volume maneuver is started. This maneuver inspires the animal to total lung capacity, hold that pressure for a short period of time, and then slowly expires the animal to residual volume (De Vleeschauwer et al. 2011, Rinaldi et al. 2012). Lung compliance is calculated from the pressure-volume curve, and an average of three signals was used for subsequent analysis.

\section{Broncho-alveolar lavage}

Lungs were lavaged four times with $1 \mathrm{ml}$ of Dulbecco's phosphate-buffered saline (PBS) and centrifuged at $1000 \mathrm{~g}$ for $10 \mathrm{~min}$ at $4^{\circ} \mathrm{C}$ ). Cytospins were colored with May-Giemsa staining to determine differential cell counts. Three hundred cells per mouse were counted to determine the number of neutrophils.

\section{Histopathology of the lungs}

The left lung was fixed in $6 \% \mathrm{v} / \mathrm{v}$ paraformaldehyde at a constant hydrostatic pressure of $25 \mathrm{~cm} \mathrm{H}_{2} \mathrm{O}$ for $24 \mathrm{~h}$ and embedded in paraffin. Sagittal sections were stained with hematoxylin and eosin to evaluate airspace enlargement quantified by mean linear intercept. The mean linear intercept was measured in 15 randomly selected fields per slide at a $200 \times$ magnification and calculated as the total length of the grid lines $\times$ random fields divided by the sum of the alveolar intercepts (Dunnill 1964).

\section{Serum measurements}

Blood was drawn from the vena cava and centrifuged at $9300 \boldsymbol{g}$ for $10 \mathrm{~min}$ at $4^{\circ} \mathrm{C}$. 25-(OH)D serum levels were measured by liquid-phase radioimmunoassay.

\section{Muscle mass}

The soleus, extensor digitorum longus (EDL), and gastrocnemius muscles from both hindlimbs were weighed and mass of left and right muscles was summed and presented in the Results section.

\section{In vitro muscle contractile properties}

In vitro contractile properties were assessed in the left soleus and EDL muscles, as described previously (Matuszczak et al. 2004, Rinaldi et al. 2012). Briefly, contractility was measured in vitro at $37^{\circ} \mathrm{C}$ using a temperature-controlled organ bath and stimulating electrodes. Optimal muscle length (Lo) for peak twitch force was established and the following measurements were performed at Lo: (i) maximum twitch force, (ii) maximum tetanic force $(300 \mathrm{~Hz})$, and (iii) force-frequency relationship at 1, $30,50,80,150$, and $250 \mathrm{~Hz}$. Twitch half-relaxation time was calculated. Lo was measured as well as bundle weight. Absolute (in gram) and specific (normalized for cross-sectional area) forces were used for analysis. Crosssectional area was calculated by muscle weight divided by specific density $\left(1.056 \mathrm{~g} / \mathrm{cm}^{2}\right)$ and muscle Lo.

\section{Muscle histology}

Right soleus and EDL muscles were frozen in isopentane cooled by liquid nitrogen and stored at $-80^{\circ} \mathrm{C}$. To determine the dimensions and proportions of the different muscle fibers, serial cross sections of $5 \mu \mathrm{m}$ thickness were blocked $(10 \% \mathrm{v} / \mathrm{v}$ normal goat serum in PBS) for $1 \mathrm{~h}$. Afterwards, the slides were incubated at room temperature for $2 \mathrm{~h}$ with a primary antibody cocktail, specific to laminin (ab11575, Abcam), myosin heavy chain (MHC)-1 (BA-F8), MHC2A (SC-71), and MHC2B (BF-F3) in the blocking buffer. All MHC antibodies were purchased from Developmental Studies Hybridoma Bank (Iowa City, IA, USA). After washing, the slides were incubated for $1 \mathrm{~h}$ with a secondary antibody cocktail (Alexa Fluor 532, Alexa Fluor 350, Alexa Fluor 488, and Alexa Fluor 555, Life Technologies) in the blocking buffer. The sections were mounted with cover slips with ProLong Gold antifade reagent (Life Technologies). Using a computerized image system (CellSens, Olympus), about 150 fibers per muscle were used to determine the dimensions and proportions of the different fibers.

\section{Myosin-to-actin ratio}

Myosin-to-actin ratio was measured at 18 weeks in the gastrocnemius muscle. Muscle samples $( \pm 40 \mathrm{mg}$ ) were homogenized using a glass homogenizer in $1 \mathrm{ml}$ of a $250 \mathrm{mmol} / \mathrm{L}$ sucrose buffer (in $\mathrm{mmol} / \mathrm{L}$ : 250 sucrose, $100 \mathrm{KCl}$, five EDTA, 20 imidazole, $\mathrm{pH}$ 6.8) on ice (Hasten et al. 1998). The homogenate was centrifuged at $1200 \mathrm{~g}$ for $10 \mathrm{~min}$, and the supernatant was discarded. The pellet was suspended in $1 \mathrm{ml}$ of a $0.5 \%$ Triton X-100 solution (175 mmol/L KCl, 0.5\% v/v Triton X-100, pH 6.8). The suspension was homogenized and centrifuged as described before. The resultant pellet was rinsed with $1 \mathrm{ml}$ of wash

Published by Bioscientifica Ltd. 
buffer $(150 \mathrm{mmol} / \mathrm{L} \mathrm{KCl}, 20 \mathrm{mmol} / \mathrm{L}$ Tris, $\mathrm{pH} \mathrm{7.0)}$. After centrifugation, the pellet was suspended in $200 \mu \mathrm{l}$ of wash buffer. Protein concentration was measured according to Bradford method. Proteins were separated on an $8 \%$ $\mathrm{v} / \mathrm{v}$ polyacrylamide gel. Myosin and actin were detected using Coomassie blue staining and semi-quantified using a computerized image system (Bio1D, VilberLourmat, Marne-La-Vallée, France).

\section{VDR expression}

VDR expression of the soleus and EDL muscles was measured by immuno staining at 18 weeks. Muscle sections of $5 \mu \mathrm{m}$ thickness were simultaneously fixed and permeabilized by incubation in 3\% v/v paraformaldehyde and $0.1 \% \mathrm{v} / \mathrm{v}$ Triton X-100 in PBS for $30 \mathrm{~min}$ (Girgis et al. 2014). After thorough washing in PBS, sections were then blocked (10\% v/v normal goat serum in PBS) for $30 \mathrm{~min}$ and incubated with a mouse monoclonal VDR antibody (sc-13133, SantaCruz Biotechnology) in the blocking buffer at $4^{\circ} \mathrm{C}$ overnight. Sections were then blocked for $30 \mathrm{~min}$ at room temperature and subsequently incubated for $1 \mathrm{~h}$ in PBS with secondary antibody (Alexa Fluor 488, Life Technologies). Afterwards, sections were incubated with 4',6-diamidino-2-phenylindole (Life Technologies) for $5 \mathrm{~min}$ to stain nuclei. The sections were mounted with cover slips with ProLong Gold antifade reagent. Images were taken using a computerized image system (CellSens, Olympus). VDR expression was blindly quantified as the number of positive spots per 150 muscle fibers.

\section{Oxidative stress measurement}

During the lipid peroxidation cascade, the primary adduct that is formed is 4-hydroxy-2-nonenal (4HNE). Using immunoblotting, $4 \mathrm{HNE}$ was measured in the gastrocnemius muscle as an index of lipid peroxidation. Therefore, frozen gastrocnemius samples $( \pm 10 \mathrm{mg})$ were homogenized in a buffer containing $5 \mathrm{mM}$ Tris- $\mathrm{HCl}$ and $5 \mathrm{mM}$ EDTA (pH7.5). The homogenates were centrifuged at $4^{\circ} \mathrm{C}$ for $20 \mathrm{~min}$ at $10,000 \mathrm{~g}$. After centrifugation, supernatant was collected and protein content was determined by Bradford method. Proteins ( $20 \mu \mathrm{g}$ per lane) were separated on a $7.5 \%$ SDSpolyacrylamide gel and blotted onto a polyvinylidene difluoride membrane. Afterwards, the blots were incubated overnight at $4^{\circ} \mathrm{C}$ with a monoclonal mouse anti 4-HNE antibody (MAB3249, R\&D Systems) and subsequently with a polyclonal rabbit anti-mouse secondary antibody (p0260, DAKO) for $1 \mathrm{~h}$ at room temperature. Proteins were detected using chemiluminescent peroxidase substrate (according to the manufacturer's instructions, Amersham) and imaged with the Proxima 2850T imaging system (Isogen Life Technologies, De Meern, The Netherlands). Four bands per sample were quantified using the TotalLab 1D (Isogen Life Technologies).

\section{Statistical analyses}

Statistical analyses were performed using a SAS 9.3 Statistical Package (SAS Institute, Cary, NC, USA). To test for normality, the Shapiro-Wilk test was applied. Comparisons between the four groups of animals were performed using two-way ANOVA with the inclusion of an interaction term between smoking and vitamin D serum levels, followed by a Tukey's post hoc test. $P$ values

A
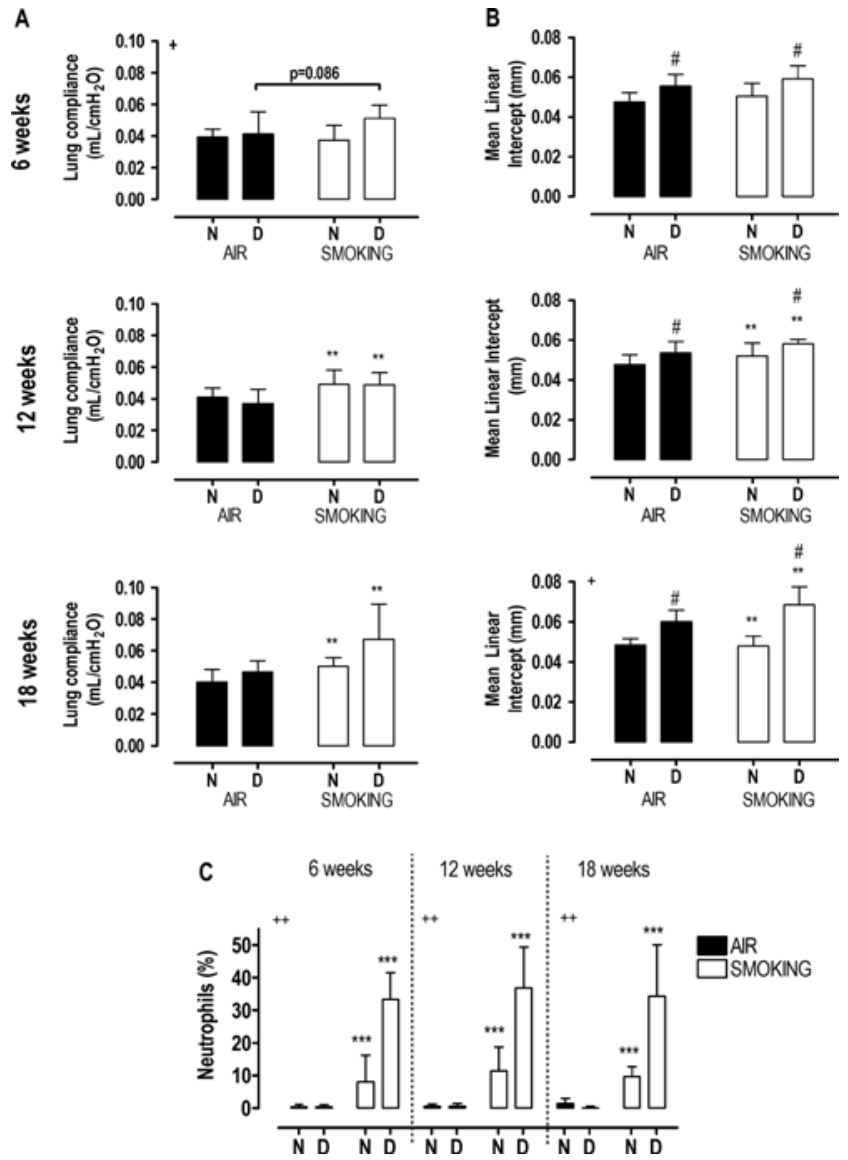

Figure 1

Lung compliance (A), mean linear intercept (B) and neutrophils (C) in broncho-alveolar lavage fluid at 6,12 , and 18 weeks in mice with normal (N) or deficient (D) levels of vitamin $D$, breathing room air (black bars) or exposed to cigarette smoke (white bars). Values are mean \pm S.D. ${ }^{* *} P<0.001$ and $* * * P<0.0001$ : effect of smoking; $\# P<0.01$ effect of vitamin $D$ deficiency. Interaction between vitamin $D$ deficiency and smoking $(+P<0.05$ and $++P<0.0001)$.

Published by Bioscientifica Ltd. 
$<0.05$ were considered to be statistically significant. Data are expressed as mean \pm s.D.

\section{Results}

\section{Serum measurements}

The vitamin D serum levels (25-(OH)D) were 75\% lower in the vitamin D-deficient mice $(18 \pm 7 \mathrm{ng} / \mathrm{ml})$ compared with the mice with normal vitamin D levels $(77 \pm 13 \mathrm{ng} / \mathrm{ml}$; $P<0.0001)$.
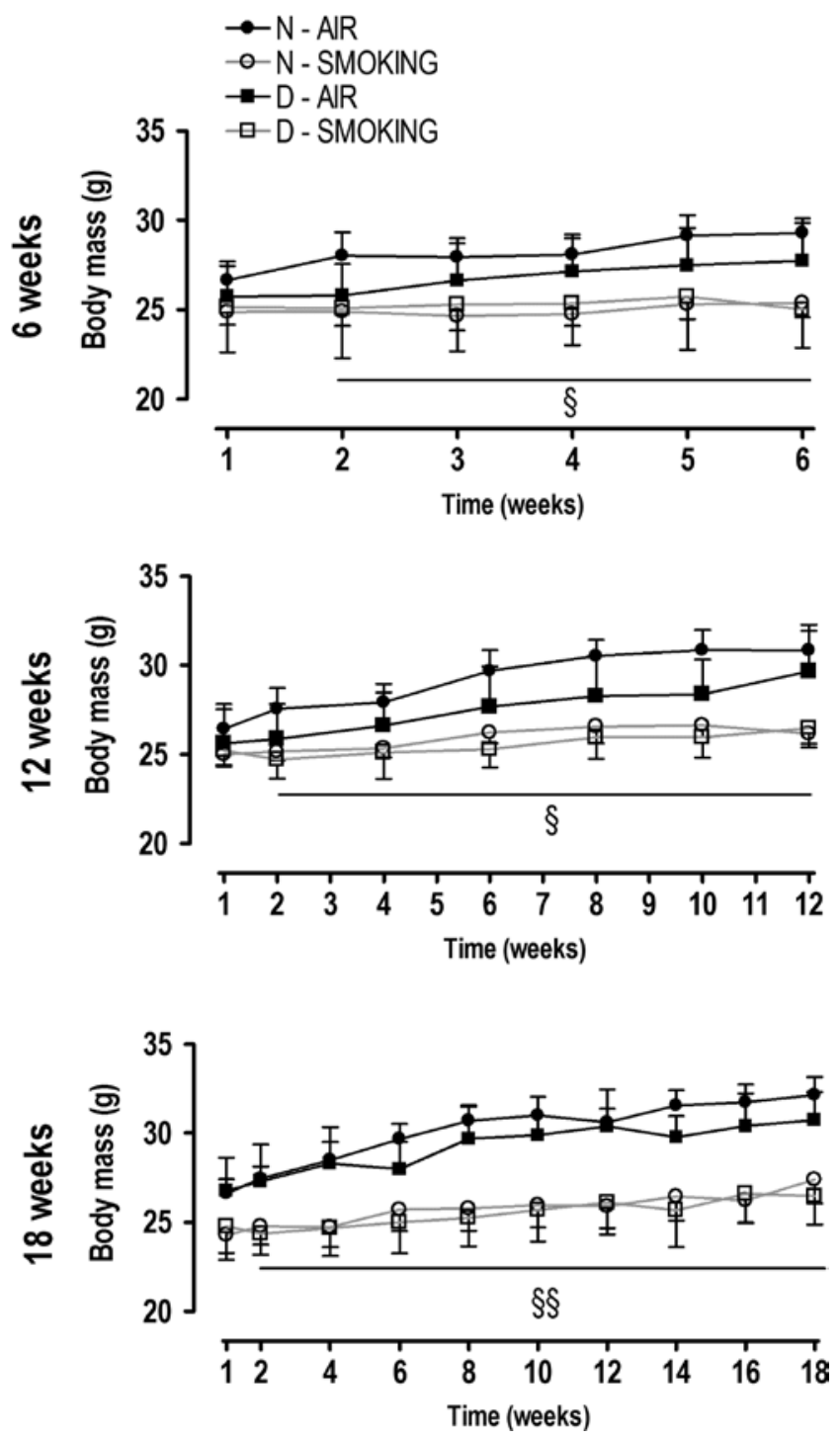

Figure 2

Body mass evolution after 6,12 , and 18 weeks in mice with normal ( $N$, circles) or deficient ( $D$, squares) levels of vitamin $D$, breathing room air (closed symbols) or exposed to cigarette smoke (open symbols). Values are mean \pm S.D. Body mass evolution with interaction between time and body mass (two way ANOVA and post hoc): $\S P<0.05$ smokers vs $\mathrm{N}$-air and $\S \S P<0.0001$ smokers vs air.

\section{Pulmonary disease}

A trend toward increased lung compliance (+24\%) was observed after 6 weeks of smoking in the vitamin D-deficient mice compared with vitamin D-deficient mice breathing air $(P=0.086$, interaction term $P<0.05)$, while after 12 and 18 weeks, lung compliance was enhanced with smoking $(P<0.001)$, with no additional effect of vitamin D deficiency (Fig. 1A). Mean linear intercept increased similarly after 12 and 18 weeks of smoking $(+7 \%, P<0.05)$, and was higher at each time point in vitamin D deficiency groups $(P<0.01)$. Moreover, a synergic increase in mean linear intercept was observed after 18 weeks when vitamin D deficiency was combined with smoking (interaction term $P=0.02$; Fig. $1 \mathrm{~B}$ and Supplementary Figure 1, see section on supplementary data at the end of this article). Smoking caused a shift toward increased number of neutrophils at each time point $(P<0.0001)$, and this effect was more pronounced in vitamin $D$-deficient smoking mice (interaction term $P<0.0001$; Fig. 1C). In addition, the number of macrophages reduced with smoking at all time points (-8\%, pooled values), and this reduction was also more pronounced with vitamin D deficiency $(-40 \%$, pooled
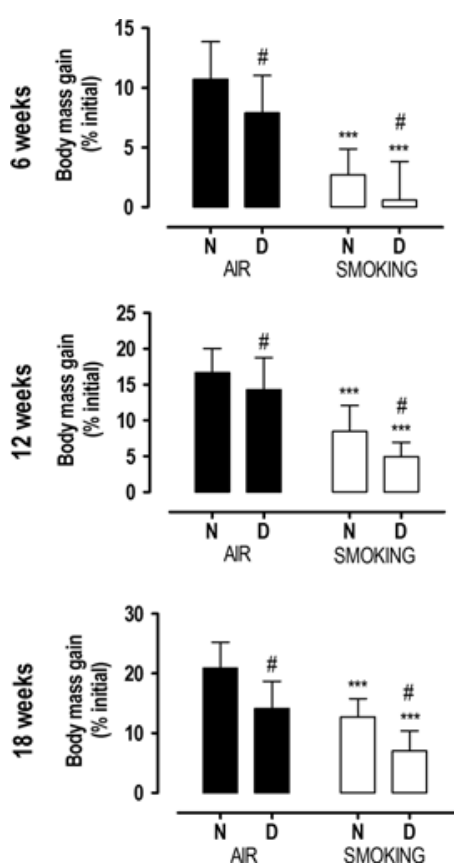

Figure 3

Body mass gain after 6,12 , and 18 weeks in mice with normal $(\mathrm{N})$ or deficient (D) levels of vitamin $D$, breathing room air (black bars) or exposed to cigarette smoke (white bars). Values are mean \pm s.D. $* * * P<0.0001$ effect of smoking; $\# P<0.01$ effect of vitamin $D$ deficiency. There is no interaction between vitamin $D$ deficiency and smoking.

Published by Bioscientifica Ltd. 
Table 1 Muscle mass (mg) of extensor digitorum longus (EDL), soleus (SO), and gastrocnemius (GA) muscles. Muscle mass in mice with normal or deficient vitamin D levels, breathing room air (air) or exposed to cigarette smoke (smoking) during 6, 12, and 18 weeks. Values expressed as the sum of left and right muscle mass. Values are mean \pm s.D.

\begin{tabular}{|c|c|c|c|c|c|}
\hline & \multicolumn{2}{|c|}{ Air } & \multicolumn{2}{|c|}{ Smoking } & \multirow[b]{2}{*}{ Interaction term } \\
\hline & Normal & Deficient & Normal & Deficient & \\
\hline \multicolumn{6}{|c|}{6 weeks } \\
\hline EDL & $22.0 \pm 1.1$ & $23.7 \pm 2.5$ & $20.8 \pm 1.4^{a}$ & $22.5 \pm 2.0^{a}$ & \\
\hline SO & $20.5 \pm 1.9$ & $22.8 \pm 1.7$ & $18.9 \pm 1.2^{a}$ & $20.3 \pm 2.4^{a}$ & \\
\hline GA & $262.9 \pm 21.9$ & $280.8 \pm 18.0$ & $240.3 \pm 13.1^{a}$ & $262.8 \pm 21.0^{a}$ & \\
\hline \multicolumn{6}{|c|}{12 weeks } \\
\hline EDL & $22.9 \pm 1.3$ & $25.3 \pm 2.0$ & $20.9 \pm 1.7^{b}$ & $23.5 \pm 1.3^{b}$ & \\
\hline SO & $21.3 \pm 1.9$ & $23.6 \pm 2.1$ & $19.8 \pm 1.7^{a}$ & $21.4 \pm 1.5^{a}$ & \\
\hline GA & $267.4 \pm 16.5$ & $285.7 \pm 20.8$ & $245.7 \pm 23.1^{b}$ & $258.5 \pm 18.4^{b}$ & \\
\hline \multicolumn{6}{|c|}{18 weeks } \\
\hline EDL & $24.6 \pm 2.2$ & $26.9 \pm 2.0$ & $21.6 \pm 1.6^{c}$ & $23.5 \pm 2.4^{c}$ & \\
\hline so & $22.6 \pm 2.0$ & $24.7 \pm 2.2$ & $20.4 \pm 1.6^{c}$ & $19.7 \pm 2.2^{c}$ & d \\
\hline GA & $281.9 \pm 22.7$ & $282.0 \pm 18.6$ & $242.5 \pm 15.3^{c}$ & $249.0 \pm 18.2^{c}$ & \\
\hline
\end{tabular}

${ }^{*} P<0.05, \mathrm{~b} P<0.001$ and $c P<0.0001$ effect of smoking. Interaction between vitamin $\mathrm{D}$ deficiency and smoking $(\mathrm{d} P=0.0295)$

values). Finally, number of lymphocytes increased only when vitamin D deficiency was combined with smoking ( $+5 \%$, pooled values; data not shown).
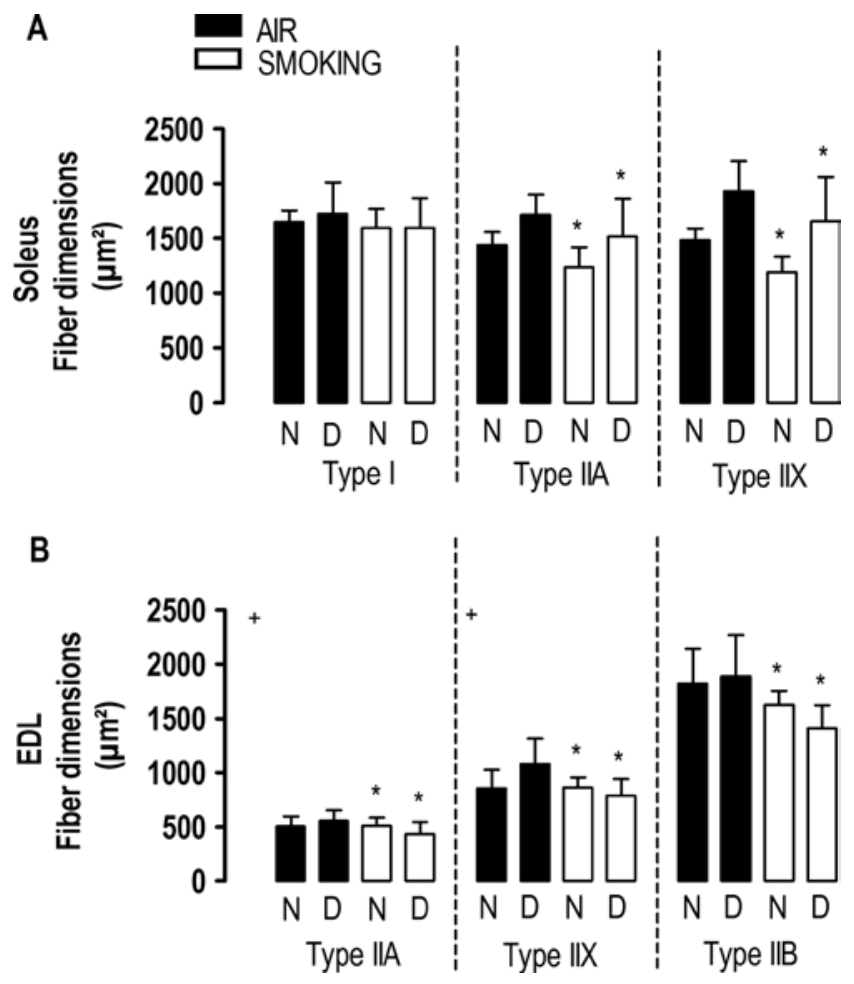

Figure 4

Fiber dimensions of the soleus (A) and EDL (B) muscle after 18 weeks in mice with normal (N) or deficient (D) vitamin $D$ levels, breathing room air (black bars) or exposed to cigarette smoke (white bars). Values are mean \pm S.D. ${ }^{*} P<0.05$ effect of smoking. Interaction between vitamin $D$ deficiency and smoking $(+P<0.05)$.

\section{Body and muscle mass}

Starting body mass (week 0) was lower in vitamin D-deficient mice $(24.4 \pm 2.0 \mathrm{~g})$ compared with mice with normal vitamin D levels $(26.7 \pm 0.9 \mathrm{~g} ; P<0.0001)$. All mice gradually increased their body mass, but from the second week already, mice in smoking condition exhibited a reduced mass gain (Fig. 2) compared with those in nonsmoking condition (interaction term $P<0.05$ ). Moreover, at each time point, body mass gain was lower in vitamin D-deficient mice compared with the non-deficient groups (Fig. 3; $P<0.01$ ), which resulted in the lowest body mass gain in vitamin D-deficient smoking mice at every single time point. Despite the independent effect of smoking and vitamin D deficiency on body mass gain, there was no significant statistical interaction $(P>0.4)$.

While vitamin D deficiency did not alter muscle mass, smoking reduced EDL mass ( -6 to $-13 \%$ ), gastrocnemius mass ( -7 to $-13 \%)$, and soleus mass ( -9 to $-15 \%)$ at 6,12 , and 18 weeks compared with air-breathing mice (Table 1 ). At 18 weeks of smoking, loss of soleus mass was highest only when vitamin $\mathrm{D}$ deficiency was combined with smoking, compared with mice with normal vitamin D levels $(-20 \%$ vs $-10 \%$, interaction term $P=0.0295$; Table 1 ).

\section{Muscle histology}

Vitamin D deficiency did not alter fiber proportions or fiber type dimensions of either muscles at any time point. Although smoking did not affect fiber proportions, it reduced the dimensions of all the type II fibers of the soleus muscle at 12 and 18 weeks (Fig. 4A) and of EDL

Published by Bioscientifica Ltd 
Table 2 Maximal tetanic force in absolute $(\mathrm{g})$ and specific $\left(\mathrm{g} / \mathrm{cm}^{2}\right)$ values of the extensor digitorum longus (EDL) and soleus (SO) muscles. Maximal tetanic force in mice with normal or deficient vitamin D levels, breathing room air (air) or exposed to cigarette smoke (smoking) during 6, 12, and 18 weeks. Values are expressed as mean \pm s.D.

\begin{tabular}{|c|c|c|c|c|c|c|c|c|c|}
\hline & \multicolumn{4}{|c|}{ Air } & \multicolumn{4}{|c|}{ Smoking } & \multirow[b]{3}{*}{ Interaction term } \\
\hline & \multicolumn{2}{|c|}{ Normal } & \multicolumn{2}{|c|}{ Deficient } & \multicolumn{2}{|c|}{ Normal } & \multicolumn{2}{|c|}{ Deficient } & \\
\hline & Absolute & Specific & Absolute & Specific & Absolute & Specific & Absolute & Specific & \\
\hline \multicolumn{10}{|c|}{6 weeks } \\
\hline EDL & $37 \pm 5$ & $4156 \pm 773$ & $37 \pm 4$ & $3748 \pm 597$ & $35 \pm 6$ & $4252 \pm 819$ & $41 \pm 3$ & $4520 \pm 374$ & \\
\hline SO & $21 \pm 3$ & $2769 \pm 533$ & $24 \pm 5$ & $2567 \pm 735$ & $22 \pm 4$ & $2778 \pm 524$ & $24 \pm 5$ & $2877 \pm 508$ & \\
\hline \multicolumn{10}{|c|}{12 weeks } \\
\hline EDL & $38 \pm 8$ & $4609 \pm 907$ & $33 \pm 6$ & $3393 \pm 757 a$ & $35 \pm 5$ & $4303 \pm 479$ & $38 \pm 4$ & $4182 \pm 740^{a}$ & c \\
\hline so & $28 \pm 3$ & $3742 \pm 348$ & $26 \pm 5$ & $2850 \pm 494^{b}$ & $25 \pm 4$ & $3654 \pm 512$ & $25 \pm 6$ & $3095 \pm 759 b$ & \\
\hline \multicolumn{10}{|c|}{18 weeks } \\
\hline EDL & $43 \pm 4$ & $4926 \pm 353$ & $30 \pm 9 b$ & $2967 \pm 929 b$ & $38 \pm 3$ & $4618 \pm 596$ & $30 \pm 10^{b}$ & $3216 \pm 1175^{b}$ & \\
\hline SO & $25 \pm 3$ & $3111 \pm 505$ & $21 \pm 8$ & $2124 \pm 782^{a}$ & $24 \pm 4$ & $3183 \pm 486$ & $22 \pm 7$ & $2595 \pm 822^{a}$ & \\
\hline
\end{tabular}

$\mathrm{a} P<0.01$ and $\mathrm{b} P<0.0001$ effect of vitamin $\mathrm{D}$ deficiency. Interaction term between vitamin $\mathrm{D}$ deficiency and smoking $(c P=0.0249)$.

muscle at 18 weeks $(P<0.05$; Fig. $4 \mathrm{~B}$ and Supplementary Figure 2). In the EDL muscle, an interaction term between vitamin D deficiency and smoking was observed in atrophy of the type IIa (interaction term $P=0.0487$ ) and the type IIx fibers (interaction term $P=0.0174)$ after 18 weeks.

\section{Muscle contractile properties}

Despite its effects on muscle mass and fiber type dimensions, smoking did not affect contractility of both muscles at any time point, even when muscle force was expressed in absolute values (not corrected for cross-sectional area; Table 2). This was also the case for vitamin D deficiency at 6 weeks. However, after 12 and 18 weeks, specific but not absolute force of the soleus muscle was lower at high stimulation frequencies in vitamin D-deficient mice breathing room air (Fig. 5A and Table 2). This was similar for the EDL muscle at 12 weeks (interaction term $P=0.0249$ ) while EDL absolute and specific forces were both reduced at 18 weeks in vitamin D-deficient groups $(P<0.0001$; Fig. $5 \mathrm{~A}$ and Table 2) in both smoking and air-exposed conditions. When looking at the loss of contractility by comparing specific force generated at 18 weeks with that at 6 weeks, a significant drop in both soleus and EDL forces was observed in all vitamin D-deficient conditions, which contrasted with the moderate gain in specific muscle force in smoking mice (Fig. 5B). Overall, we found no significant interaction between smoking and vitamin D deficiency on muscle force in either the EDL or soleus muscle. Neither smoking nor vitamin $\mathrm{D}$ deficiency affected twitch half-relaxation time (data not shown).
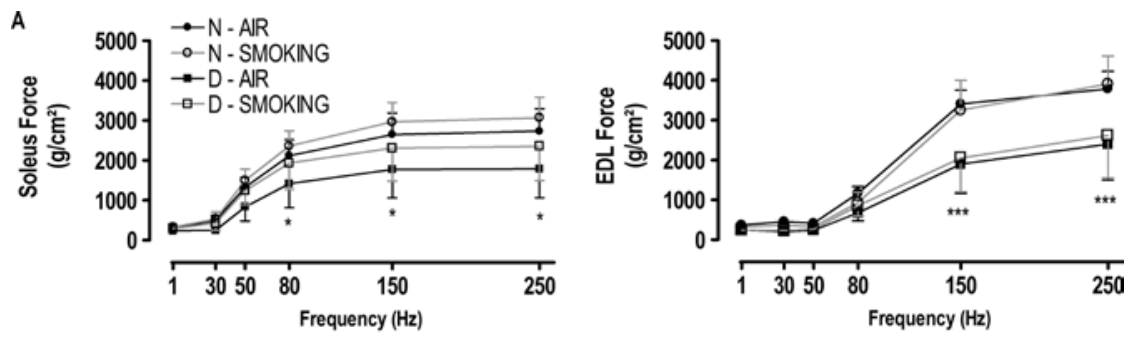

Figure 5

Force-frequency curve (A) of the soleus and extensor digitorum longus (EDL) muscles at 18 weeks in mice with normal (circles) or deficient (squares) vitamin $\mathrm{D}$ levels breathing room air (closed symbols) or exposed to cigarette smoke (open symbols). Values are mean \pm s.D. Interaction between frequency and force (two way ANOVA and post hoc): ${ }^{*} P<0.05$ $D$-air vs $N$; $* * * P<0.0001$ deficient vs normal. Maximal tetanic force differences $(\Delta)(B)$ of the soleus and EDL muscles between 18 and 6 weeks in mice with normal (N) or deficient (D) vitamin $\mathrm{D}$ levels, breathing room air (black bars) or exposed to cigarette smoke (white bars). Values are mean \pm S.D. and expressed as percentage difference between 18 and 6 weeks. $* * P<0.01$ and $* * * P<0.0001$ effect of vitamin $D$ deficiency. There is no interaction between vitamin $D$ deficiency and smoking.

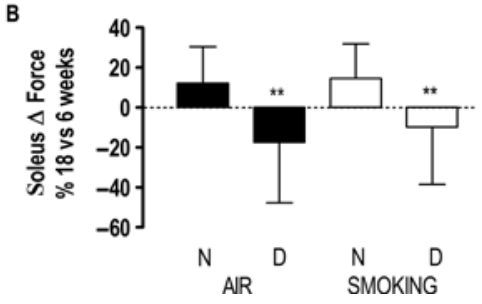

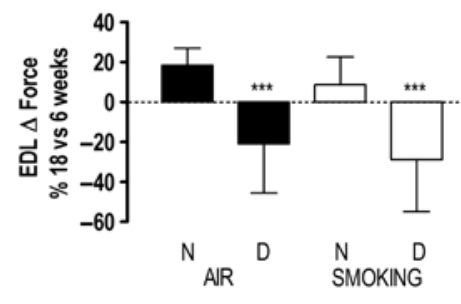

(c) 2016 Society for Endocrinology Printed in Great Britain http://joe.endocrinology-journals.org DOI: 10.1530/JOE-15-0491 


\section{VDR expression}

Smoking did not affect VDR expression. By contrast, VDR expression in both EDL and soleus muscles was reduced in vitamin D-deficient mice compared with mice with normal vitamin D levels $(P<0.0001)$, with no effect of smoking (Fig. 6A and Supplementary Figure 3). The reduction in VDR expression with vitamin D deficiency was more pronounced in the soleus muscle $(-57 \%)$ compared with the EDL muscle $(-37 \%$; interaction term $P<0.05)$.

\section{Myosin-to-actin ratio}

At 18 weeks, myosin and actin content of the gastrocnemius muscle was similar whatever the conditions. As a consequence, neither smoking nor vitamin D deficiency had an effect on the myosin-to-actin ratio of the gastrocnemius muscle (Fig. 6B).

\section{Oxidative stress}

In the gastrocnemius muscle, smoking increased lipid peroxidation, as shown by the $15 \%$ increase in $4 \mathrm{HNE}$ adduct formation $(P=0.06)$. Vitamin $\mathrm{D}$ deficiency increased $4 \mathrm{HNE}$ with $33 \%(P<0.001$; Fig. $6 \mathrm{C})$, but there was no interaction effect between smoking and vitamin $\mathrm{D}$ deficiency on $4 \mathrm{HNE}$ adduct formation.
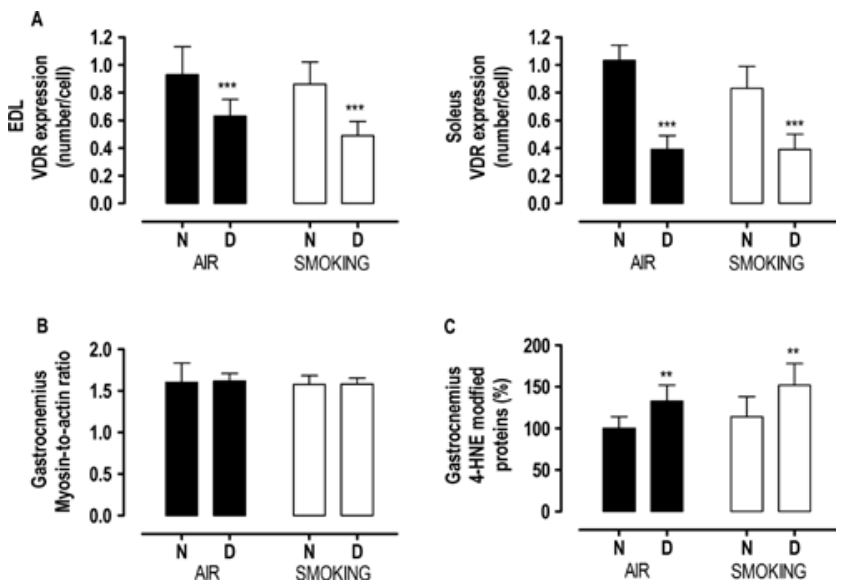

\section{Figure 6}

Vitamin D receptor (VDR) expression (A) in extensor digitorum longus and soleus muscles, myosin-to-actin ratio in the gastrocnemius muscle (B) and 4-hydroxy-2-nonenal modified protein (C) in the gastrocnemius muscle after 18 weeks in mice with normal $(\mathrm{N})$ or deficient $(D)$ vitamin $D$ levels, breathing room air (black bars) or exposed to cigarette smoke (white bars). Values are mean \pm s.D. Values are expressed as percentage form $\mathrm{N}$-air in Fig. $5 \mathrm{C}$. $* * P<0.001$ and $* * * P<0.0001$ effect of vitamin $\mathrm{D}$ deficiency. There is no interaction between vitamin $D$ deficiency and smoking.

\section{Discussion}

This is the first study examining the effects of vitamin D deficiency on skeletal muscle function in a smoking mouse model. In this study, we show that smoking causes early emphysema in vitamin D-deficient mice, with more pronounced lung inflammation and more tissue destruction at 18 weeks of follow-up. We also show that vitamin D deficiency and smoking exert different effects on skeletal muscles. Whereas smoking resulted in a loss of body and muscle mass and fiber atrophy, vitamin D deficiency affected muscle force of both EDL and soleus muscles. As a consequence, the combination of chronic cigarette smoke exposure and long-lasting vitamin D deficiency resulted in the poorest skeletal muscle conditions at 4.5 months of follow-up.

As expected, smoking caused the development of emphysema (Rinaldi et al. 2012) and lung inflammation (Vlahos et al. 2006, Hansen et al. 2013). In addition, body mass started to reduce shortly after initiation of smoking (De Paepe et al. 2008, Tang et al. 2010, Barreiro et al. 2012, Rinaldi et al. 2012, Caron et al. 2013, Hansen et al. 2013), and loss of muscle mass was present at all time points in all muscle types (EDL, soleus, and gastrocnemius muscles; De Paepe et al. 2008, Tang et al. 2010, Barreiro et al. 2012). We also observed atrophy of all type II fibers after 18 weeks in the EDL muscle, and from 12 weeks onward in the soleus muscle, while fiber proportions remained unaffected. This pattern of changes corresponds to what is observed in patients with moderate COPD (Hughes et al. 1983, Satta et al. 1997). Moreover, our data are in line with the increased expression of pro-atrophy-related genes, such as Atrogin-1, Murf1, and Usp19, reported in the skeletal muscle of smoking rodents (Tang et al. 2010, Liu et al. 2011, Caron et al. 2013). Even though muscle mass was reduced and fiber type dimensions were smaller in the smoking conditions, it did not result in muscle force impairment as both absolute and specific forces were preserved. Our data indicate that smoking mainly induced muscle wasting with no repercussion on muscle function.

Although body mass gain was lower in the vitamin D-deficient mice, mass of EDL, soleus, and gastrocnemius muscle was not reduced. This is in line with several studies carried out in vitamin D-deficient rats in which calcium and phosphorus serum levels were maintained within the normal range (Bhat et al. 2013, Ceglia et al. 2013). Interestingly, we observed a reduced contractility in both muscle types from 12 weeks onward in the vitamin D-deficient conditions. This loss of force was not related

Published by Bioscientifica Ltd. 
to muscle wasting, because neither muscle mass loss nor fiber atrophy was present. Moreover, muscle force was impaired in vitamin D-deficient conditions even when corrected for cross-sectional area. Until now, previous reports indicated that the detrimental effects of vitamin $\mathrm{D}$ deficiency on muscle force only occurred when coupled with phosphorus deficiency, because restoring phosphorus levels normalized muscle force (Schubert \& DeLuca 2010). Similarly, others suggested that hypocalcemia induced by profound vitamin $\mathrm{D}$ deficiency either did not reduce muscle force (Schubert \& DeLuca 2010) or was not the only factor responsible (Pleasure et al. 1979). As calcium and phosphorus serum levels were maintained within the normal range throughout the diet, the observed effects in the current study pertain to vitamin D deficiency per se.

We then attempted to understand how vitamin D deficiency may lead to muscle dysfunction. First, because vitamin $\mathrm{D}$ plays a role in regulating contractile proteins (Girgis et al. 2013), vitamin D deficiency might result in impaired contractility through alterations in key contractile proteins. Indeed, previous studies have shown that the content of actomyosin was reduced in vitamin D-deficient rats (Stroder 1966), as was actin in vitamin D-deficient chicks (De Boland et al. 1983). However, the expression of two major contractile proteins in skeletal muscles, actin and myosin, was not influenced by vitamin D serum levels, indicating that this could not explain the observed reduced muscle force in vitamin D-deficient animals.

Secondly, vitamin D deficiency is known to alter muscle contraction kinetics by reducing calcium reuptake into the sarcoplasmic reticulum, thereby leading to a prolongation of the relaxation phase of muscle contraction (Rodman \& Baker 1978). As a consequence, less calcium is released from the sarcoplasmic reticulum upon a new muscle contraction. In this way, vitamin D deficiency may impair muscle force. In the current study, we indirectly assessed whether calcium reuptake was altered by measuring twitch half-relaxation time, as an index of muscle relaxation. Because twitch half-relaxation time was identical in the muscles of mice with normal and low vitamin D levels, it is unlikely that vitamin D deficiency affected muscle force by altering calcium reuptake in the sarcoplasmic reticulum.

Thirdly, through binding to its receptor (VDR), vitamin D may have an impact on muscle contraction by activating genes implicated in protein synthesis and by initiating complex second messenger pathways that influence calcium flux. Interestingly, a positive association between serum vitamin $\mathrm{D}$ levels and VDR concentration has been reported in skeletal muscle of animals (Domingues-Faria et al. 2014), in skeletal muscle cell lines (Girgis et al. 2014) and also in human muscle biopsies (Pojednic et al. 2015). As vitamin D deficiency results in downregulation of VDR expression, impairment of muscle contraction may be expected after vitamin $\mathrm{D}$ deficiency. In the current study, we indeed observed a downregulation of the VDR with vitamin D deficiency in both muscles, which could eventually explain the loss of muscle force with vitamin D deficiency. However, as the downregulation of VDR was more severe in the soleus muscle $(-57 \%)$ compared with the EDL muscle $(-37 \%)$, while the loss of muscle force was more pronounced in the EDL muscle compared with the soleus muscle, reduced VDR expression could not fully explain force impairment with vitamin D deficiency.

Finally, knowing that vitamin D or vitamin D analogs are able to limit oxidative stress in animals (Hamden et al. 2009, Husain et al. 2009, Tanaka et al. 2011) and keeping in mind that serum levels of vitamin $\mathrm{D}$ were found to be related with the activity of antioxidant enzymes in rat gastrocnemius muscle (Gonzalez-Reimers et al. 2010), we explored whether vitamin D deficiency may have affected muscle force in our study by enhancing muscle oxidative stress. In fact, mild oxidative stress as shown by increased protein oxidation and nitrosative stress and reduced activities of the antioxidant enzymes has been reported in the muscles of vitamin D-deficient rats (Bhat $\&$ Ismail 2015). In the current study, we assessed $4 \mathrm{HNE}$ as an index of lipid peroxidation. We observed an increase in 4HNE with vitamin D deficiency, indicating that vitamin $\mathrm{D}$ deficiency per se may have affected skeletal muscle function by enhancing oxidative stress. Intriguingly, because the activity of several antioxidant enzymes is higher in the type I oxidative fibers, compared with the more glycolytic type II fibers (Powers et al. 1994), it is suggested that the type II fibers are likely to be more vulnerable to oxidative stress. This might explain why loss of muscle force with vitamin D deficiency is higher in the EDL muscle (containing 100\% type II fibers) compared with the soleus muscle (containing 63\% type II fibers).

In addition to the clear interactions between smoking and vitamin D deficiency on lung inflammation and emphysema progression, a synergic effect of vitamin D deficiency with smoking was observed on the loss of soleus mass after 18 weeks. The soleus muscle might be particularly vulnerable to the combination of vitamin D deficiency and cigarette smoking due to its fiber composition. Indeed, the soleus muscle contains approximately $37 \%$ type I fibers, which are mainly

Published by Bioscientifica Ltd 
affected by cigarette smoking (Montes de Oca et al. 2008), and $63 \%$ type II fibers, which are affected by vitamin D deficiency (Augusto et al. 2004, Bloemberg \& Quadrilatero 2012, Ceglia \& Harris 2013). Surprisingly, type II fiber atrophy was slightly more pronounced in the EDL muscle when vitamin D deficiency was combined with smoking. It is, however, important to mention that this effect was only present in the type IIa and IIx fibers, which represent about one third of all the fibers. The effect was definitely too low to affect EDL mass. Finally, vitamin D deficiency combined with smoking did not aggravate the reduction in muscle force in either muscles.

Although the current mouse model reflects a mild form of the human disease in terms of a lung disease, our data are particularly relevant for patients with COPD in whom limb muscle adaptation to COPD consists of a fiber shift toward a type II profile. Interestingly, these type II fibers seem to be preferentially affected in our model, as shown by predominant fiber atrophy with smoking, and the potentially higher vulnerability for oxidative damage. In humans, it is pertinent becuase type II fibers are the first to be recruited to prevent falling (Ceglia \& Harris 2013), and falling remains a problematic concern in patients with COPD. Moreover, vitamin $\mathrm{D}$ deficiency has been repeatedly associated with falls and meta-analyses clearly show a beneficial effect of vitamin D supplementation on fall prevention in the general population (Bischoff-Ferrari et al. 2009, Murad et al. 2011). Our data may corroborate with these clinical findings and suggest that selective dysfunction of muscles containing predominantly type II muscle fibers may occur with vitamin D deficiency in patients with COPD.

In the current study, the serum levels of $25-(\mathrm{OH}) \mathrm{D}$ were four times lower in the vitamin D-deficient mice compared with mice with normal vitamin D levels. A similar drop in serum levels of $25-(\mathrm{OH}) \mathrm{D}$ has been previously reported in mice fed with a vitamin D-deficient diet (Crane-Godreau et al. 2013, Domingues-Faria et al. 2014). As these deficient levels are fivefold higher than what is usually targeted for studying the immunological defects, the current observations are linking skeletal muscle dysfunction to milder but long-lasting deficiencies throughout life. This is particularly relevant for the elderly COPD populations in whom moderate deficiency $(10-20 \mathrm{ng} / \mathrm{ml})$ is much more prevalent as compared with levels less than $10 \mathrm{ng} / \mathrm{ml}$ (Ramavat 1999, Paterson \& Ayoub 2014) in case of rickets, which is known to present with muscle dysfunction (Torres et al. 1986, Veilleux et al. 2013).
In conclusion, although smoking mainly in general caused loss of muscle mass, moderate vitamin D deficiency was associated with muscle dysfunction in a muscle type dependent manner. Both factors clearly contribute to a worse health status of the skeletal muscle in a smoking mouse model of mild COPD.

\section{Supplementary data}

This is linked to the online version of the paper at http://dx.doi.org/10.1530/ JOE-15-0491.

Declaration of interest

The authors declare that there is no conflict of interest that could be perceived as prejudicing the impartiality of the research reported.

\section{Funding}

This work was supported by the Research fund of the KULeuven (OT/11/088) and AstraZeneca Pharmaceuticals.

\section{References}

Agusti AG, Sauleda J, Miralles C, Gomez C, Togores B, Sala E, Batle S $\&$ Busquets X 2002 Skeletal muscle apoptosis and weight loss in chronic obstructive pulmonary disease. American Journal of Respiratory and Critical Care Medicine 166 485-489. (doi:10.1164/ rccm.2108013)

Augusto V, Padovani CR \& Rocha Campos GE 2004 Skeletal muscle fiber types in C57Bl6J mice. Brazilian Journal of Morphological Sciences 21 89-94.

Barreiro E, del Puerto-Nevado L, Puig-Vilanova E, Perez-Rial S, Sanchez F, Martinez-Galan L, Rivera S, Gea J, Gonzalez-Mangado N \& Peces-Barba G 2012 Cigarette smoke-induced oxidative stress in skeletal muscles of mice. Respiratory Physiology \& Neurobiology 182 9-17. (doi:10.1016/j.resp.2012.02.001)

Bhat M \& Ismail A 2015 Vitamin D treatment protects against and reverses oxidative stress induced muscle proteolysis. Journal of Steroid Biochemistry and Molecular Biology 152 171-179. (doi:10.1016/ j.jsbmb.2015.05.012)

Bhat M, Kalam R, Qadri SS, Madabushi S \& Ismail A 2013 Vitamin D deficiency-induced muscle wasting occurs through the ubiquitin proteasome pathway and is partially corrected by calcium in male rats. Endocrinology 154 4018-4029. (doi:10.1210/en.2013-1369)

Bischoff-Ferrari HA, Borchers M, Gudat F, Durmuller U, Stahelin HB \& Dick W 2004a Vitamin D receptor expression in human muscle tissue decreases with age. Journal of Bone and Mineral Research 19 265-269.

Bischoff-Ferrari HA, Dietrich T, Orav EJ, Hu FB, Zhang Y, Karlson EW \& Dawson-Hughes B 2004b Higher 25-hydroxyvitamin D concentrations are associated with better lower-extremity function in both active and inactive persons aged $>$ or $=60 \mathrm{y}$. American Journal of Clinical Nutrition 80 752-758.

Bischoff-Ferrari HA, Dawson-Hughes B, Staehelin HB, Orav JE, Stuck AE, Theiler R, Wong JB, Egli A, Kiel DP \& Henschkowski J 2009 Fall prevention with supplemental and active forms of vitamin $\mathrm{D}$ : a meta-analysis of randomised controlled trials. BMJ 339 b3692. (doi:10.1136/bmj.b3692)

Published by Bioscientifica Ltd. 
Bloemberg D \& Quadrilatero J 2012 Rapid determination of myosin heavy chain expression in rat, mouse, and human skeletal muscle using multicolor immunofluorescence analysis. PLoS One 7 e35273. (doi:10.1371/journal.pone.0035273)

Caron MA, Morissette MC, Theriault ME, Nikota JK, Stampfli MR \& Debigare R 2013 Alterations in skeletal muscle cell homeostasis in a mouse model of cigarette smoke exposure. PLoS One 8 e66433. (doi:10.1371/journal.pone.0066433)

Ceglia L \& Harris SS 2013 Vitamin D and its role in skeletal muscle. Calcified Tissue International 92 151-162. (doi:10.1007/s00223-0129645-y)

Ceglia L, Rivas DA, Pojednic RM, Price LL, Harris SS, Smith D, Fielding RA \& Dawson-Hughes B 2013 Effects of alkali supplementation and vitamin D insufficiency on rat skeletal muscle. Endocrine 44 454-464. (doi:10.1007/s12020-013-9976-0)

Crane-Godreau MA, Black CC, Giustini AJ, Dechen T, Ryu J, Jukosky JA Lee HK, Bessette K, Ratcliffe NR, Hoopes PJ, et al. 2013 Modeling the influence of vitamin D deficiency on cigarette smokeinduced emphysema. Frontiers in Physiology 4 132. (doi:10.3389/ fphys.2013.00132)

Cutillas-Marco E, Fuertes-Prosper A, Grant WB \& Morales-Suarez-Varela M 2012 Vitamin D deficiency in South Europe: effect of smoking and aging. Photodermatology, Photoimmunology \& Photomedicine $\mathbf{2 8}$ 159-161. (doi:10.1111/j.1600-0781.2012)

Decramer M, Gosselink R, Troosters T, Verschueren M \& Evers G 1997 Muscle weakness is related to utilization of health care resources in COPD patients. European Respiratory Journal 10 417-423. (doi:10.1183/09031936.97.10020417)

De Boland AR, Albornoz LE \& Boland R 1983 The effect of cholecalciferol in vivo on proteins and lipids of skeletal muscle from rachitic chicks. Calcified Tissue International 35 798-805. (doi:10.1007/BF02405126)

De Paepe B, Brusselle GG, Maes T, Creus KK, D’hose S, D’Haese N, Bracke KR, D'hulst AI, Joos GF \& De Bleecker JL 2008 TNF alpha receptor genotype influences smoking-induced muscle-fibre-type shift and atrophy in mice. Acta Neuropathologica 115 675-681. (doi:10.1007/s00401-008-0348-4)

De Vleeschauwer SI, Rinaldi M, De Vooght V, Vanoirbeek JA, Vanaudenaerde BM, Verbeken EK, Decramer M, Gayan-Ramirez GN, Verleden GM \& Janssens W 2011 Repeated invasive lung function measurements in intubated mice: an approach for longitudinal lung research. Laboratory Animal 45 81-89. (doi:10.1258/la.2010.010111)

Domingues-Faria C, Chanet A, Salles J, Berry A, Giraudet C, Patrac V, Denis P, Bouton K, Goncalves-Mendes N, Vasson MP, et al. 2014 Vitamin D deficiency down-regulates Notch pathway contributing to skeletal muscle atrophy in old wistar rats. Nutrition \& Metabolism 11 47. (doi:10.1186/1743-7075-11-47)

Doucet M, Russell AP, Leger B, Debigare R, Joanisse DR, Caron MA, LeBlanc P \& Maltais F 2007 Muscle atrophy and hypertrophy signaling in patients with chronic obstructive pulmonary disease. American Journal of Respiratory and Critical Care Medicine 176 261-269. (doi:10.1164/rccm.200605-704OC)

Dunnill MS 1964 Evaluation of a simple method of sampling the lung for quantitative histological analysis. Thorax 19 443-448.

Endo I, Inoue D, Mitsui T, Umaki Y, Akaike M, Yoshizawa T, Kato S \& Matsumoto T 2003 Deletion of vitamin D receptor gene in mice results in abnormal skeletal muscle development with deregulated expression of myoregulatory transcription factors. Endocrinology 144 5138-5144.

Engelen MP, Schols AM, Does JD \& Wouters EF 2000 Skeletal muscle weakness is associated with wasting of extremity fat-free mass but not with airflow obstruction in patients with chronic obstructive pulmonary disease. American Journal of Clinical Nutrition $\mathbf{7 1}$ 733-738.

Girgis CM, Clifton-Bligh RJ, Hamrick MW, Holick MF \& Gunton JE 2013 The roles of vitamin D in skeletal muscle: form, function, and metabolism. Endocrine Reviews 34 33-83. (doi:10.1210/er.2012-1012)
Girgis CM, Mokbel N, Cha KM, Houweling PJ, Abboud M, Fraser DR, Mason RS, Clifton-Bligh RJ \& Gunton JE 2014 The vitamin D receptor (VDR) is expressed in skeletal muscle of male mice and modulates 25-hydroxyvitamin D (25OHD) uptake in myofibers. Endocrinology 155 3227-3237. (doi:10.1210/en.2014-1016)

Gonzalez-Reimers E, Duran-Castellon MC, Lopez-Lirola A, Santolaria-Fernandez F, Abreu-Gonzalez P, Alvisa-Negrin J \& Sanchez-Perez MJ 2010 Alcoholic myopathy: vitamin D deficiency is related to muscle fibre atrophy in a murine model. Alcohol and Alcoholism 45 223-230. (doi:10.1093/alcalc/agq010)

Gosselink R, Troosters T \& Decramer M 1996 Peripheral muscle weakness contributes to exercise limitation in COPD. American Journal of Respiratory and Critical Care Medicine 153 976-980. (doi:10.1164/ ajrccm.153.3.8630582)

Hamden K, Carreau S, Jamoussi K, Miladi S, Lajmi S, Aloulou D, Ayadi F \& Elfeki A 2009 1Alpha,25 dihydroxyvitamin D3: therapeutic and preventive effects against oxidative stress, hepatic, pancreatic and renal injury in alloxan-induced diabetes in rats. Journal of Nutritional Science and Vitaminology 55 215-222. (doi:10.3177/jnsv.55.215)

Hansen MJ, Chen H, Jones JE, Langenbach SY, Vlahos R, Gualano RC, Morris MJ \& Anderson GP 2013 The lung inflammation and skeletal muscle wasting induced by subchronic cigarette smoke exposure are not altered by a high-fat diet in mice. PLoS One $\mathbf{8}$ e80471. (doi:10.1371/journal.pone.0080471)

Hasten DL, Morris GS, Ramanadham S \& Yarasheski KE 1998 Isolation of human skeletal muscle myosin heavy chain and actin for measurement of fractional synthesis rates. American Journal of Physiology 275 E1092-E1099.

Hopkinson NS, Li KW, Kehoe A, Humphries SE, Roughton M, Moxham J, Montgomery H \& Polkey MI 2008 Vitamin D receptor genotypes influence quadriceps strength in chronic obstructive pulmonary disease. American Journal of Clinical Nutrition $\mathbf{8 7}$ 385-390.

Hughes RL, Katz H, Sahgal V, Campbell JA, Hartz R \& Shields TW 1983 Fiber size and energy metabolites in five separate muscles from patients with chronic obstructive lung diseases. Respiration 44 321-328. (doi:10.1159/000194564)

Husain K, Ferder L, Mizobuchi M, Finch J \& Slatopolsky E 2009 Combination therapy with paricalcitol and enalapril ameliorates cardiac oxidative injury in uremic rats. American Journal of Nephrology 29 465-472. (doi:10.1159/000178251)

Jackson AS, Shrikrishna D, Kelly JL, Kemp SV, Hart N, Moxham J, Polkey MI, Kemp P \& Hopkinson NS 2013 Vitamin D and skeletal muscle strength and endurance in COPD. European Respiratory Journal 41 309-316. (doi:10.1183/09031936.00043112)

Janssens W, Lehouck A, Carremans C, Bouillon R, Mathieu C \& Decramer M 2009 Vitamin D beyond bones in chronic obstructive pulmonary disease: time to act. American Journal of Respiratory and Critical Care Medicine 179 630-636. (doi:10.1164/rccm.200810-1576PP)

Janssens W, Bouillon R, Claes B, Carremans C, Lehouck A, Buysschaert I, Coolen J, Mathieu C, Decramer M \& Lambrechts D 2010 Vitamin D deficiency is highly prevalent in COPD and correlates with variants in the vitamin D-binding gene. Thorax 65 215-220. (doi:10.1136/ thx.2009.120659)

Johnson LE \& DeLuca HF 2002 Reproductive defects are corrected in vitamin d-deficient female rats fed a high calcium, phosphorus and lactose diet. Journal of Nutrition 132 2270-2273.

Li YC, Pirro AE, Amling M, Delling G, Baron R, Bronson R \& Demay MB 1997 Targeted ablation of the vitamin D receptor: an animal model of vitamin D-dependent rickets type II with alopecia. PNAS 94 9831-9835. (doi:10.1073/pnas.94.18.9831)

Liu Q, Xu WG, Luo Y, Han FF, Yao XH, Yang TY, Zhang Y, Pi WF \& Guo XJ 2011 Cigarette smoke-induced skeletal muscle atrophy is associated with up-regulation of USP-19 via p38 and ERK MAPKs. Journal of Cellular Biochemistry 112 2307-2316. (doi:10.1002/ jcb.23151) 
Maltais F, Decramer M, Casaburi R, Barreiro E, Burelle Y, Debigare R, Dekhuijzen PN, Franssen F, Gayan-Ramirez G, Gea J, et al. 2014 An official American Thoracic Society/European Respiratory Society statement: update on limb muscle dysfunction in chronic obstructive pulmonary disease. American Journal of Respiratory and Critical Care Medicine 189 e15-e62. (doi:10.1164/rccm.201402-0373ST)

Matuszczak Y, Arbogast S \& Reid MB 2004 Allopurinol mitigates muscle contractile dysfunction caused by hindlimb unloading in mice. Aviation, Space, and Environmental Medicine 75 581-588.

Montes de Oca M, Loeb E, Torres SH, De Sanctis J, Hernandez N \& Talamo C 2008 Peripheral muscle alterations in non-COPD smokers. Chest 133 13-18. (doi:10.1378/chest.07-1592)

Murad MH, Elamin KB, Abu Elnour NO, Elamin MB, Alkatib AA, Fatourechi MM, Almandoz JP, Mullan RJ, Lane MA, Liu H, et al. 2011 Clinical review: The effect of vitamin D on falls: a systematic review and meta-analysis. Journal of Clinical Endocrinology and Metabolism 96 2997-3006. (doi:10.1210/jc.2011-1193)

Paterson CR \& Ayoub D 2014 Congenital rickets due to vitamin D deficiency in the mothers. Clinical Nutrition 34 793-798. (doi:10.1016/j.clnu.2014.12.006)

Petersen AM, Magkos F, Atherton P, Selby A, Smith K, Rennie MJ, Pedersen BK \& Mittendorfer B 2007 Smoking impairs muscle protein synthesis and increases the expression of myostatin and MAFbx in muscle. American Journal of Physiology: Endocrinology and Metabolism 293 E843-E848.

Plant PJ, Brooks D, Faughnan M, Bayley T, Bain J, Singer L, Correa J, Pearce D, Binnie M \& Batt J 2010 Cellular markers of muscle atrophy in chronic obstructive pulmonary disease. American Journal of Respiratory Cell and Molecular Biology 42 461-471. (doi:10.1165/ rcmb.2008-03820C)

Pleasure D, Wyszynski B, Sumner A, Schotland D, Feldman B, Nugent N, Hitz K \& Goodman DB 1979 Skeletal muscle calcium metabolism and contractile force in vitamin D-deficient chicks. Journal of Clinical Investigation 64 1157-1167.

Pojednic RM, Ceglia L, Olsson K, Gustafsson T, Lichtenstein AH, Dawson-Hughes B \& Fielding RA 2015 Effects of 1,25dihydroxyvitamin D3 and vitamin D3 on the expression of the vitamin d receptor in human skeletal muscle cells. Calcified Tissue International 96 256-263. (doi:10.1007/s00223-014-9932-x)

Powers SK, Criswell D, Lawler J, Ji LL, Martin D, Herb RA \& Dudley G 1994 Influence of exercise and fiber type on antioxidant enzyme activity in rat skeletal muscle. American Journal of Physiology 266 R375-R380.

Ramavat LG 1999 Vitamin D deficiency rickets at birth in Kuwait. Indian Journal of Pediatrics 66 37-43.

Rinaldi M, Maes K, De Vleeschauwer S, Thomas D, Verbeken EK, Decramer M, Janssens W \& Gayan-Ramirez GN 2012 Long-term nose-only cigarette smoke exposure induces emphysema and mild skeletal muscle dysfunction in mice. Disease Models \& Mechanisms 5 333-341. (doi:10.1242/dmm.008508)

Rodman JS \& Baker T 1978 Changes in the kinetics of muscle contraction in vitamin D-depleted rats. Kidney International 13 189-193. (doi:10.1038/ki.1978.28)

Satta A, Migliori GB, Spanevello A, Neri M, Bottinelli R, Canepari M, Pellegrino MA \& Reggiani C 1997 Fibre types in skeletal muscles of chronic obstructive pulmonary disease patients related to respiratory function and exercise tolerance. European Respiratory Journal 10 $2853-2860$
Savkur RS, Bramlett KS, Stayrook KR, Nagpal S \& Burris TP 2005 Coactivation of the human vitamin $\mathrm{D}$ receptor by the peroxisome proliferator-activated receptor gamma coactivator-1 alpha. Molecular Pharmacology 68 511-517.

Schubert L \& DeLuca HF 2010 Hypophosphatemia is responsible for skeletal muscle weakness of vitamin D deficiency. Archives of Biochemistry and Biophysics 500 157-161. (doi:10.1016/j. abb.2010.05.029)

Simpson K, Killian K, McCartney N, Stubbing DG \& Jones NL 1992 Randomised controlled trial of weightlifting exercise in patients with chronic airflow limitation. Thorax 47 70-75. (doi:10.1136/thx.47.2.70)

Song Y, Kato S \& Fleet JC 2003 Vitamin D receptor (VDR) knockout mice reveal VDR-independent regulation of intestinal calcium absorption and $\mathrm{ECaC} 2$ and calbindin D9k mRNA. Journal of Nutrition $\mathbf{1 3 3}$ 374-380.

Stroder J 1966 The content of actomyosin in the skeletal muscle of rats with experimentally induced rickets. Helvetica Paediatrica Acta 21 323-326.

Swallow EB, Reyes D, Hopkinson NS, Man WD, Porcher R, Cetti EJ, Moore AJ, Moxham J \& Polkey MI 2007 Quadriceps strength predicts mortality in patients with moderate to severe chronic obstructive pulmonary disease. Thorax 62 115-120. (doi:10.1136/ thx.2006.062026)

Tanaka M, Tokunaga K, Komaba H, Itoh K, Matsushita K, Watanabe H, Kadowaki D, Maruyama T, Otagiri M \& Fukagawa M 2011 Vitamin D receptor activator reduces oxidative stress in hemodialysis patients with secondary hyperparathyroidism. Therapeutic Apheresis and Dialysis 15 161-168. (doi:10.1111/j.1744-9987.2010.00890.x)

Tang K, Wagner PD \& Breen EC 2010 TNF-alpha-mediated reduction in PGC-1alpha may impair skeletal muscle function after cigarette smoke exposure. Journal of Cellular Physiology 222 320-327. (doi:10.1002/jcp.21955)

Torres CF, Forbes GB \& Decancq GH 1986 Muscle weakness in infants with rickets: distribution, course, and recovery. Pediatric Neurology 2 95-98.

Uh ST, Koo SM, Kim YK, Kim KU, Park SW, Jang AS, Kim dJ, Kim YH \& Park CS 2012 Inhibition of vitamin d receptor translocation by cigarette smoking extracts. Tuberculosis and Respiratory Diseases $\mathbf{7 3}$ 258-265. (doi:10.4046/trd.2012.73.5.258)

Veilleux LN, Cheung MS, Glorieux FH \& Rauch F 2013 The muscle-bone relationship in X-linked hypophosphatemic rickets. Journal of Clinical Endocrinology and Metabolism 98 E990-E995. (doi:10.1210/jc.2012-4146)

Visser M, Deeg DJ \& Lips P 2003 Low vitamin D and high parathyroid hormone levels as determinants of loss of muscle strength and muscle mass (sarcopenia): the Longitudinal Aging Study Amsterdam. Journal of Clinical Endocrinology and Metabolism 88 5766-5772. (doi:10.1210/ jc.2003-030604)

Vlahos R, Bozinovski S, Jones JE, Powell J, Gras J, Lilja A, Hansen MJ, Gualano RC, Irving L \& Anderson GP 2006 Differential protease, innate immunity, and NF-kappaB induction profiles during lung inflammation induced by subchronic cigarette smoke exposure in mice. American Journal of Physiology: Lung Cellular and Molecular Physiology 290 L931-L945.

Yoshizawa T, Handa Y, Uematsu Y, Takeda S, Sekine K, Yoshihara Y, Kawakami T, Arioka K, Sato H, Uchiyama Y, et al. 1997 Mice lacking the vitamin D receptor exhibit impaired bone formation, uterine hypoplasia and growth retardation after weaning. Nature Genetics $\mathbf{1 6}$ 391-396.

Received in final form 3 February 2016

Accepted 23 February 2016

Accepted Preprint published online 23 February 2016 http://joe.endocrinology-journals.org DOI: 10.1530/JOE-15-0491
(C) 2016 Society for Endocrinology Printed in Great Britain 